\title{
The Investigation of Grass-roots Demand about the Land Policy
}

\author{
Yanwen $\mathrm{Xu}$ * \\ School of Business, Jianghan University, Wuhan Hubei P.R.China 430056 \\ *Corresponding author: Yanwen Xu, Master, xuyw1121@163.com
}

\begin{abstract}
:
Through the differentiation and analysis of the degree, channels, and focuses for grass-roots to understand national land policy during urbanization process, from the perspective of supply side of policy information, the research discovers that local government should put more efforts and dedications to promote and construe land policy. In terms of demanders, the occupation, gender, age, education, etc. of residents will affect how they understand and master the policy in question. It is advised that the policy should be further promoted, understood, and constructed through multiple methods to strictly define the scope of land requisition with a new concept of sharable development and enable the grass-roots to get and share more legitimate income.
\end{abstract}

Key words: land policy; policy requirement; system supply

\section{Introduction}

By 2020, the total number of landless farmers in China will exceed 100 million among which more than 50 million will lose jobs and lands, bringing overwhelming challenges to social transformation. During the process of broad urbanization, the grass-roots, especially residents dwelling in rural-urban fringe should pay great attention to significant questions, including how to legally and appropriately collect rural collective land, deal with the adjustment of farmland division, make reasonable arrangement of housing problems of rural migrant population and external population, and properly solve basic housing, living, and employment problems of land-loss farmers. The paper attempts to provide decisions and proposals for the practical implementation of central policy and related laws and regulations and promote the transformation from theoretical good policy to practical good policy through the investigation of the actual understanding of land policies and information by grass-roots as well as administrative levels and direction of policy requirements to guarantee effective system supply.

\section{Investigation and analysis of land policy's demand}

As a common issue, the study has designed research questions in order to find out whether the grassroots can smoothly acquire a variety of policy documents (public accessible) issued by the government. Five options respectively corresponding to Grade 1-5 in Likert Scale have been prepared for the question, "can you acquire the detailed information of policy documents issued by the government”, ranging from totally inaccessible to totally accessible. Through statistical methods, we can make quantitative evaluation on the difficulty level of grass-roots in the interview region to acquire the information of policy documents, and the results are 
shown in Table 1. From the table, it is obvious that the proportion of "slightly accessible" accounting for $44.2 \%$ is the largest, the proportion of "totally accessible" accounting for $4.4 \%$ is the smallest, but the proportion of "totally inaccessible" reaches up to $16.5 \%$. The mean value of the samples is 2.47, and the median is 2 (namely corresponding grassroots can only obtain a small part of policy information), which signifies that the ability to acquire policy information falls between "slightly accessible" and "totally accessible". Therefore, the ability of grass-roots to be aware of policy content and acquire policy information should be improved.

Table 1 Status Quo for Grassroots to Acquire Information about Policy Document

\begin{tabular}{l|l|r|r|r|r}
\hline & Frequency & Percentage & Effective percentage & Cumulative percentage \\
\hline \multirow{2}{*}{ Effective } & Totally inaccessible & 143 & 16.5 & 16.5 & 16.5 \\
\cline { 2 - 6 } & Slightly accessible & 383 & 44.2 & 44.2 & 60.7 \\
\cline { 2 - 6 } & Mostly accessible & 168 & 19.4 & 19.4 & 80.1 \\
\cline { 2 - 6 } & Substantially accessible & 134 & 15.5 & 15.5 & 95.6 \\
\cline { 2 - 6 } & Totally accessible & 38 & 4.4 & 4.4 & 100.0 \\
\cline { 2 - 6 } & Total & 866 & 100.0 & 100.0 & \\
\hline
\end{tabular}

Table 2 Status Quo for Grassroots to Acquire Information about Policy Document (based on cross-over analysis of the gender of respondents)

\begin{tabular}{l|r|r|r}
\hline & \multicolumn{2}{|c|}{ Gender of respondents } & \multicolumn{2}{c}{ Total } \\
\hline Totally inaccessible & \multicolumn{1}{|c|}{ Male } & \multicolumn{1}{c|}{ Female } & \multicolumn{1}{c}{ Tot } \\
Slightly accessible & 216 & 61 & 143 \\
Mostly accessible & 106 & 167 & 383 \\
Substantially accessible & 85 & 62 & 168 \\
Totally accessible & 26 & 49 & 134 \\
\hline Total & 515 & 351 & 38 \\
\hline
\end{tabular}

Table 3 Status Quo for Grassroots to Acquire Information about Policy Document (based on crossover analysis of the age of respondents)

\begin{tabular}{l|r|r|r}
\hline Age of respondents & Mean value & \multicolumn{1}{c|}{ N } & Standard deviation \\
\hline Below 25 & 2.2658 & 301 & .997 \\
$25-35$ & 2.4440 & 241 & 1.055 \\
$36-55$ & 2.7259 & 270 & 1.130 \\
Above 55 & 2.4423 & 52 & 1.055 \\
Total & 2.4699 & 864 & 1.074 \\
\hline
\end{tabular}

Table 2 shows that men are better in obtaining policy theoretical information than women, which reflects the characteristic of "male bread-earner". It can be found from Table 3, population of 36-55 year old are equipped with better abilities to get access to policy information, and young people under the age of 25 is the worst, which may reveal that young 
people focus on school work rather than policy theory.

Table 4 Status Quo for Grassroots to Acquire Information about Policy Document (based on crossover analysis of the identity of respondents)

\begin{tabular}{l|r|r|r}
\hline & \multicolumn{2}{|c|}{ Identity of respondents } & \multirow{2}{*}{ Total } \\
\cline { 2 - 4 } & Cadre at the basic level & The masses & 143 \\
\hline Totally inaccessible & 10 & 133 & 143 \\
Slightly accessible & 40 & 343 & 383 \\
Mostly accessible & 26 & 142 & 168 \\
Substantially accessible & 33 & 101 & 134 \\
Totally accessible & 15 & 23 & 38 \\
Total & 124 & 742 & 866 \\
\hline
\end{tabular}

Table 5 Status Quo for Grassroots to Acquire Information about Policy Document (based on crossover analysis of the identity of respondents)

\begin{tabular}{l|r|r|r}
\hline \multicolumn{1}{c|}{ Identity of respondents } & Mean value & $\mathrm{N}$ & Standard deviation \\
\hline Cadre at the basic level & 3.0242 & 124 & 1.185 \\
The masses & 2.3774 & 742 & 1.026 \\
Total & 2.4700 & 866 & 1.073 \\
\hline
\end{tabular}

From Table 4 and Table 5, cadres at the basic level have a better acknowledge of the content of policy documents than general public, which depends on the professional characteristics and job responsibilities. . Table 4 also shows that Chinese communist party members also have a better acknowledge of the content of policy documents than others. In conclusion, party cadres at low levels enjoy the advantage and play a greater role in promotion and explanation of policy theory.

From Table 6, we can conclude that urban and married residents and those genetically related to undergraduate members can be better and easier in the acquisition of theoretical policy information. With the increase in household income, the corresponding situation will be improved a lot. Residents in system enjoy more opportunities to acquire policy documents than others.

From Likert Scale, we can identify the frequency of basic-level theory learning or preaching by community or sub-district office and obtain general mean value (2.2) after statistic, and in detail, the mean values for urban community and rural community are respectively 2.33 and 2.02 (see Table 7). Based on the feedbacks from the demanders of information, it is obvious that grassroots generally hold that the basic-level theory learning or preaching activities by community or sub-district office are less than the expectation and far behind the actual requirements of grassroots. The data also reveal that the frequency of theory learning or 
preaching activities and other similar activities held by rural community are apparently less frequent than urban community, which may be caused by lowly-populated rural community, difficulty in activity implementation, and absence of professional personnel.

Table 6 Status Quo for Grassroots to Acquire Information about Policy Document (based on political status and other individual factors of the respondents)

\begin{tabular}{l|l|r|r|r}
\hline Influencing factor & Category Description & Mean Value & Sample number & Standard deviation \\
\hline $\begin{array}{l}\text { Political status of the } \\
\text { respondents }\end{array}$ & $\begin{array}{l}\text { Chinese communist party } \\
\text { member }\end{array}$ & 2.8466 & 176 & 1.173 \\
& Non-party member & 2.3739 & 690 & 1.026 \\
\hline Nature of registered & Rural & 2.2370 & 384 & 0.987 \\
permanent residence & Urban & 2.6556 & 482 & 1.104 \\
\hline Undergraduate & Yes & 2.5356 & 506 & 1.089 \\
families & No & 2.3778 & 360 & 1.045 \\
\hline Family income status & Low income & 2.2878 & 271 & 1.013 \\
& Middle income & 2.5295 & 508 & 1.079 \\
& High income & 2.6897 & 87 & 1.154 \\
\hline Job Nature of & In- system & 2.7292 & 240 & 1.126 \\
householder & Out-system & 2.3706 & 626 & 1.036 \\
\hline
\end{tabular}

Table 7 Frequency of Basic-Level Theory Learning or Preaching by Community

\begin{tabular}{l|r|r|r}
\hline Nature of registered permanent residence & Mean value & $\mathrm{N}$ & Standard \\
\hline Rural & 2.0235 & 383 & .87248 \\
Urban & 2.3320 & 482 & .91521 \\
Total & 2.1954 & 865 & .90905 \\
\hline
\end{tabular}

Form the survey, we can find that respondents aged over 55 years and between 25 to 35 years choose to consult basic-level or working personnel rather than self-reference. However, interviewees below 25 years or between 36 and 55 years with strong independence tend to check on relative documents. In case of cross analysis centering on undergraduate families, people with undergraduate families are obviously inclined to self-refer to relative documents (12\% higher than the counterparts), but the counterparts prefer for external consultation, indicating that with the popularization of higher education and the continuous improvement of mass cultural quality level, grassroots are prompt and proactive in the satisfaction with individual demands for policy theory. On the basis of cross analysis, we can identify the following points: (1) Males are more inclined to check on relevant policy documents than females by $4 \%$ while females are more inclined to turn to the advice from families and relatives by 5\%; (2) grassroots cadres tend to refer to relevant policy documents in person with 6\% higher than general public; (3) Party members tend to refer to relevant policy documents in person with 15\% higher than general public; (4) permanent residents in systems tend to refer to relevant policy documents in person with $12 \%$ higher than general public. 


\section{Main research conclusions}

From the current situation, more efforts should be put into the implementation of basic-level activities to promote policy theory and improve the ability of grassroots to acquire policy information. Grassroots cadres have better knowledge of the content about policy documents than general public, and it is the same with party members and permanent staff in systems than their counterparts. Therefore, it can be concluded that party cadres at low levels enjoy the advantage and play a greater role in promotion and explanation of policy theory.

The two bottlenecks seriously affecting the understanding of various theoretical policy documents by grass-roots are unsatisfactory distribution of policy theory and delayed response to general public, which may be caused by defects in the distribution and explanation of policy and the interaction between the general public and mechanism. The relevant departments should carry out work in accordance with needs of the masses, deepen reform, cater to the requirements of grassroots, and seek profits for the public.

Grassroots generally hold that the basic-level theory learning or preaching activities by community or sub-district office are less frequent than the expectation and the frequency of theory learning or preaching activities and other similar activities held by rural community are apparently less than urban community, which may be caused by lowly-populated rural community, difficulty in activity implementation, and absence of professional personnel.

Grassroots tend to live on the hump when confronted with doubts about policy theory, indicating in this new era people can take full advantage of a variety of public media and tools to communicate and interact with each other. When it comes to the solution of difficulty in the understanding of policy, instant official response plays a great role in the relief of doubts. The current main channels for grassroots to acquire national policy theory are radio, television, network, and new media, but the forms of books, newspapers, and speeches are limited. The promotion via news media has been widely accepted by the broad masses, enabling grassroots to identify and understand policy theory and providing more benefits for the public.

\section{Complete recommendations for land policy in accordance with the demand of the} masses

\subsection{To guarantee the orientation of common interest of collective land and to define the scope of land requisition}

In order to maximize the benefits of collective land expropriation, investigation and announcement procedures for land collection should be improved. Namely the investigation of collected land should be conducted, covering whether a piece of land can be collected, whether the collection of the land in question can realize established public interests, and whether the reason-ability for the collection of the land in question involves the planned location to guarantee the legitimation and compliance of land acquisition. 


\subsection{To take full account unproductive income}

Corresponding departments should follow market price and principles of optimum utilization and adopt diversified compensation methods so that unemployed farmers can share the land value-added benefits. For example, a series of innovation can be implemented in specific measures: for projects with stable income, farmers can enjoy the benefits and dividends as shareholders with land use rights, which can take into account the appreciation gains after land capitalization, avoid the maximum deviation, encourage farmers to participate in the distribution system of land value-added income and make fair adjustment in interest distribution pattern; for land acquisition projects with commercial purposes, it is advised that land users can directly and proportionately compensate land-lost peasants in cash in accordance with market value or transfer part of commercial projects to them free of charge or at lower price as per land market value.

\subsection{To perfect the compensation mechanism}

Relevant department should make prior changes in previous one-time compensation and adopt different compensation methods according to different ages: the compensation for the elderly can be distributed monthly to guarantee their long-term living; the compensation for young and middle-aged land-lost farmers can be distributed in the form of fund for production and entrepreneurship to promote their employment and entrepreneurship; the compensation for teenagers can be distributed in the form of educational fund to improve education quality. Secondly, relevant department should scientifically determine the compensation standard of land expropriation in accordance with indicators such as actual purchasing power linking up with market price of land, and State Council or local government departments should formulate and implement dynamic standards of compensation for land expropriation in accordance with market value at different periods. Finally, land-lost farmers should participate in the development and distribution of land acquisition compensation. In terms of the distribution of compensation for land acquisition, special personnel should earmark the fund for its specified purpose, and land-lost farmers should designate representatives to attend the distribution process for strong supervision.

\section{Reference}

1. H.T. Chen, Responsive Governance: Integration of Farmers' Demand and National Policy (in Chinese) [J], Journal of the Northwest Normal University,2014.6:124-129.

2. D.C. Den, Institutional Supply and Local Governments' "Free Riding"(in Chinese) [J],Research On Financial and Economic Issues ,2004.08:10-15.

3. G.Z. Fang, Constructing the New Mode about Agriculture Information Service of Supply and the Demand_-Based on Apart Areas of Shandong(in Chinese) [J], Chinese Agricultural Science Bulletin,2012,26:291-197.

4. F.Fang, X.Gao, An Empirical Analysis of Institutional Supply Theory in the New Rural Cooperative Medical System and Degrees of Farmers' Satisfaction--Based on Surveys in Z and X Villages in Hubei Province(in Chinese) [J], Journal of Huazhong Agricultural University（Social Sciences Edition）,2015, 05:89-96. 